\title{
¿Qué implicaciones tiene la discrepancia entre la edad óptima versus la edad aprobada para la vacunación contra el VPH?
}

\author{
Marion Piñeros, MD MSc \\ Instituto Nacional de Cancerología, Bogotá, Colombia
}

Correspondencia: Grupo Área Salud Pública. Calle 1 no. 9-85 Bogotá Colombia. mpineros@cancer.gov.co

Uno de los temas críticos en la implementación de la vacuna contra el VPH es la necesidad de contar con una definición clara de la edad a vacunar (1). A partir de los distintos estudios publicados y de la historia natural de la infección por VPH y cáncer de cuello uterino no cabe ninguna duda de que la recomendación para la vacunación contra el VPH es antes del inicio de las relaciones sexuales, lo que para efectos prácticos se traduce en la vacunación entre los 10 y los 15 años.

Una revisión reciente de las recomendaciones establecidas por las autoridades sanitarias en diversos países europeos, Estados Unidos y Canadá muestra cómo efectivamente el rango de edad recomendado oscila entre 9 y 17 años con una tendencia a estar entre los 12 y 14 años en la mayoría de estos países (2). En algunos de ellos se recomienda adicionalmente la vacunación de actualización (“catch-up") hasta los 24 años, con la que se espera lograr un impacto más rápido.

Sin embargo, en muchos de los países del continente africano o sudamericano que son justamente los de mayor riesgo de cáncer de cuello uterino (3), aún no se cuenta con recomendaciones gubernamentales sobre la vacunación contra VPH, a pesar de que la vacuna ya está disponible en el mercado.

El rango de edad aprobado en las licencias para comercializar las vacunas contra VPH varía no solamente entre países, sino también entre las dos vacunas existentes en este momento. Aunque con algunas va- riaciones, en la mayoría de países el rango de edad con que se aprobó Gardasil ${ }^{\mathrm{R}}$ en mujeres está entre los 9 y los 26 años y el de Cervarix ${ }^{\mathrm{R}}$ está entre los 10 y 45 años.

El rango que hay entre la edad óptima (antes del inicio de las relaciones sexuales) y la edad aprobada de comercialización (que sobrepasa la edad de inicio de las relaciones sexuales), es un rango que debe manejarse con suma cautela pues, en ausencia de información apropiada y certera en términos de los beneficios de la vacuna, puede dar lugar a conductas inadecuadas y poco éticas, en las que salen mal librados tres sectores claramente comprometidos. De un lado, se perpetúa la imagen de lucro por parte de la industria farmacéutica y de médicos particulares que aplican la vacuna; de otro lado, se puede hacer evidente una anarquía producto de la falta de un papel claro de control y modulación por parte del Estado y finalmente, se cuestiona la aplicabilidad real de los resultados de investigación para beneficio de la población.

En la brecha entre la edad óptima y la edad aprobada hay una gama de posibilidades, donde la vacuna puede representar beneficios aún para mujeres que ya han tenido varios compañeros sexuales, bien sea por mecanismos de protección cruzada a otros tipos de VPH o por ausencia de infección previa simultánea con varios tipos de VPH $(4,5)$. Sin embargo, es deber de quienes venden y aplican la vacuna en el ámbito privado informar a las mujeres sobre las posibilidades de eficacia en estas condiciones, máxime cuando aún no se 
cuenta con información de efectividad en escenarios de la "vida real", como lo menciona Juan Gervás. En países menos desarrollados es justamente la población de mayor nivel educativo y poder adquisitivo la que tiene mayores probabilidades de haber escuchado sobre la vacuna; con sorpresa vemos información dirigida a esta franja poblacional donde se establece la vacuna como "necesaria" para mujeres adultas y en la que se afirma que los hombres también "deben" vacunarse. Se corre el peligro de un uso irracional de la vacuna sobre la base del poder adquisitivo de una minoría de la población, del miedo al cáncer y del poder de convicción de los médicos que venden la vacuna.

En este escenario, si el tiempo para implementar la vacuna contra el VPH como parte de programas organizados de salud pública se torna muy largo, particularmente en países más necesitados, la inequidad ya existente con el cáncer de cuello uterino se profundizará aún más. Un paso esencial en este camino es contar con una difusión amplia de información científica a todo nivel así como con recomendaciones claras por parte de las autoridades sanitarias gubernamentales.

A nivel de América Latina, dentro del papel que también destaca Gulnar Azevedo que deben tener los gobiernos, cabe resaltar como un aporte importante la reunión “Towards Comprehensive Cervical Cancer Prevention and Control" celebrada en días pasados en México y auspiciada, entre otros, por la Organización Mundial de la Salud y la Organización Panamericana de la Salud.

\section{Referencias}

1. Piñeros M. Efectividad de la vacunación en el escenario de programas de salud publica: aspectos clave par su implementación. HPV Today $2007 ; 12: 14$.

2. Wright TC. Current status of HPV vaccination recommendations. HPV Today 2008; 14:8-9.

3. Ferlay J, Bray F, Pisani P, Parkin DM. GLOBOCAN 2002 Cancer Incidence, Mortality and Prevalence Worldwide IARC CancerBase No. 5, version 2.0 IARCPress, Lyon, 2004.
4. FUTURE II Study Group. Quadrivalent Vaccine against Human Papillomavirus to prevent High-Grade Cervical lesions. NEJM 2007;357:1928-43.

5. Harper DM, Franco EL, Wheeler CM, Moscicki AB, Romanowski B, Roteli-Martins $\mathrm{CM}$, et al. Sustained efficacy up to 4.5 years of a bivalent L1 virus-like particle vaccine against human papillomavirus types 16 and 18: follow-up from a randomised control trial. Lancet 2006;367(9518):1247-55. 